\title{
Collaboration in Buyer-Seller Relationships as a New Approach to Competitive Advantage
}

\author{
Jamila Jouali ${ }^{1}$, Abdellatif Chakor ${ }^{2}$ \\ ${ }^{1}$ PhD student - Faculty of Economic Sciences University Mohammed V-Souissi, Rabat, Morocco \\ ${ }^{2}$ Professor Authority - Faculty of Economic Sciences Morocco University Mohammed V-Souissi, Rabat, \\ Morocco
}

\begin{abstract}
Although recent academic work on business relationships often discusses relationship quality as a major subject, particularly with regard to the phenomenon of seller stratification, there is still little empirical research on this important construct. In this paper, the authors provide a thorough conceptualization of relationship quality and its possible antecedents, i.e., bond relationship, Temporal, Social, and Structural bond, drawing on an empirical base of 219 buyers questionnaires, Structural equations modeling (SEM) is used to assess the simultaneous effects of the predictive variables. An empirical survey confirms the impact of the relational bond dimension on the satisfaction. The satisfaction has an effect on the customer trust witch influence his commitment. The findings are discussed and the authors provide managerial implications for decision-makers from both buyer and supplier organizations.
\end{abstract}

Key words: Bonds, Relationship, quality relationship.

\section{INTRODUCTION:}

Collaboration is an increasingly important area of interest in the academic and the business world. Companies focus strongly on the development of closer bonds with other organizations in search of competitive advantage and improved market positioning. In business-to-business markets, long-term orientation has become one of the main issues in relationships between buyers and their sellers (Ganesan S.1994). Longterm relationships with suppliers enable firms to be more efficient in procurement as well as more effective in delivering quality and/or in reducing transaction costs (Sheth JN, Sharma A.1997). Firms can benefit from collaborating with other companies in several ways. Various theories explain the effectiveness of interorganizational cooperative arrangements. Palmatier et al. (2007) identify and compare four theoretical lenses that dominate research on inter-organizational relationships performance: Commitment - trust (e.g. Morgan and Hunt 1994), dependence (e.g. Hibbard et al. 2001), transaction cost economics (e.g. Heide and John 1990), and relational bond torbacka, Strandvik and Grönroos 1994). Relationship marketing, which focuses on approaches to building, developing, and maintaining successful relational exchanges (Morgan and Hunt, 1994; Grönroos, 1994), is changing marketing orientation from attracting short-term, discrete transactions to retaining long-lasting, intimate customer relationships. Bendapudi and Berry (1997) define relationship enhancement from a buyer's perspective as "broadening and deepening the relational bonds with the service provider. That is, the customer makes investments in the relationship to enhance it beyond the status quo. These investments might include buying additional services, providing capital, information, manpower or other resources, or participating in company events". This is due to that bonds are building blocks of relationships that affect the stability in the cooperation between the companies. If the relationships between companies are strong then it can usually be seen as a sign that the companies will cooperate for a longer time and that may affect the companies' competitive and financial strength positively (Storbacka, Strandvik and Grönroos 1994). Bonds of different kinds are said to develop between cooperating companies due to mutual adjustment between the counterparts. This affects the exchange processes between the companies, future adaptation processes and also the costs of switching to another supplier or buyer (Mattsson 1987). Morgan and Hunt (1994) thought that relationship quality is the key point of successful relationship marketing strategy. Chen (2003) suggested that relational marketing strategies of banks can enhance customer loyalty through relationship quality. This research investigated the effects of service sector suppliers' relationship bonding tactics (RBTs) on the quality relationships.

\section{RELATIONAL BOND AS SOURCE OF DIVERSIFICATION}

\section{THEORETICAL BACKGROUND}

"Bonds are the psychological, emotional, economic or psychical attachments in a relationship that are fostered by association and interaction and serve to bind parties together under relational exchange." (McCall 1970). This definition and view has then been incorporated into the industrial marketing approach e.g. By Wilson and Mummalaneni (1986). Some authors consider bonds to be exit barriers and thus 
function as value reducing factors that have a negative effect on the relationship. This is due to the entrapment the counterpart that is affected by the exit barrier in the relationship feels. This coincides with the burden of relationships idea of Håkansson and Snehota (1995). Bonds are seen as switching barriers beside customer satisfaction" (Naude \& Buttle 1999). There are different kinds of bonds in theory temporal ee e.g. Johanson \& Mattsson (1987) and Kock (1995). Social, structural (Han. 1991Berry and Parasuraman).

\section{TEMPORAL BOND}

Temporal bond is a dimension of relationships. The relationships are dynamic,it means they evolve over time. By providing a boundary for interaction and potential interactions, time acts as a container for business relationships (Medlin, 2004). The relationships are dynamic, and, over time, they evolve. Ford et al. (2003) point out four stages of relationship development: pre-relationship, exploratory, developing and stable. Although Dwyer et al. (1987) mark out full mutual awareness, exploration, expansion, commitment and dissolution stages. Ford (1980) and Dwyer et al. (1987) approaches to the last stage of relationships are different: the first researcher explains that at the final stage relations are institutionalizing, the other group of researchers highlight the break of the relationships. Grönroos (1994) refers to three stages of the process of relationship development: initiative, purchase, and use of the product. Relationship development might be described with reference to experience, uncertainty, distance and commitment (Castro et al., 2005). All these features of relationships vary during the time.

\section{SOCIAL BONDS}

Social bonds can also be employed in building a relationship between sellers and buyers. However, social bonds are weak drivers of a working exchange relationship. They may be antecedents of an exchange relationship and they may cause a relationship to continue on the level of a social relationship when an exchange relationship gets dropped in favor of a competitor. Such propositions in the literature are usually developed with the supplier's best interest in mind Turnbull and Wilson 1989). the existence of close social relationships develops a 'psychological loyalty', which is conveyed in the decisions the customer makes. Burnham et al80 call it 'relational switching costs', a type of switching cost that involves psychological or emotional discomfort because of the breaking of bonds.

Social bonds are personal ties that pertain to service dimensions that offer interpersonal interactions and friendships (Beatty and Lee, 1996; Wilson, 1995). Social bonds also serve as a motivation to continue a relationship (Lawler and Yoon, 1993). Social bonds link and hold a buyer and seller closely together (Han, 1991), and represent the degree of mutual friendship and liking shared by the buyer and seller (Wilson, 1995). Social bonding represents a greater bond than friendship or benevolence. It represents a marketing activity where the outcomes of exchange may depend on bargaining, negotiation, power, conflict, and shared meaning between buyer and seller (Bagozzi, 1978). Some aspects of social bonding such as bargaining and negotiation may occur at the beginning of a relationship, while other aspects such as shared meaning may occur later.

Social bonds see e.g. Simmel (1906), Small (1915), McCall (1970), Granovetter (1973), Håkansson (1982) and Wilson \& Mummalaneni (1986) There may be latent social bonds between the customer and the supplier before the cooperation starts. (Järvinen 1997). Social bonds are usually weak or nonexistent when the cooperation starts. These bonds develop over time when people in the companies start to know each other during the cooperation. People that interact with each other often for instance from the selling/buying sides in the company and from logistics, product development and quality assurance tend to have the strongest bonds to each other. (Wendelin 1998a) (Wendelin 1998b) By conducting business together and learning to know each other also in the spare time. Through for instance "wining and dining" these bonds grow stronger.

\section{STRUCTURAL BOND}

Structural bonds are created because each party needs their partner in order to accomplish something; these bonds bring the members together, keep them together, and cause them to interact in a relationship (Han, 1998). Structural bonding can be defined as applying, marketing programs that create value to the customer and either require investments by the buyer that cannot be salvaged if the relationship ends, and/or may be expensive if the buyers must supply this service themselves if they change sources" (Turnbull and Wilson 1989). Berry (1995) theorized that there are three levels to RM. Level one relies on pricing incentives to create customer loyalty. The likelihood of ongoing competitive advantage is low as price is easily matched by a competitor. Level two relies on social bonds; however aggressive pricing may also be used at this level. Level three involves structural solutions to customer problems. This includes value-added benefits that are difficult or expensive for customers to achieve on their own. Berry (1995) contended that companies should identify customers most likely to be receptive to RM as it involves fixed and variable cost. It follows that structural bonds exist only after the relationship has been in existence for some time and that they bond and tie partners together from that point forward through the maintenance of the relationship. Turnbull and Wilson (1989) 
studied the impact of social and structural bonds in customer relationships in the manufactured hospital products industry. They defined structural bonds as those that occur between two parties that make investments that cannot be retrieved when the relationship ends. Structural bonds can also occur when complexities such as supplier-provided expertise drives up the switching costs. Social bonds are positive interpersonal relationships between the buyer and seller. In business-to-business relationships, structural bonds and gains from synergetic effects can commonly be found. Just-in-time production and lean production are examples in which the partners hope to gain efficiency and/or effectiveness. To make a co-operation work, all partners ,accept some degree of obligation - and therefore give some degree of assurance with respect to their future conduct" (Richardson 1972, p. 886). Co-operation and structural bonds in business-to-business are viewed as essential components of supplier-customer-relationships seen as a network (Anderson, Hakansson and Johansen 1994).

\section{QUALITY RELATIONSHIP}

Relationship quality refers to a customer's perceptions of how well the whole relationship fulfills the expectations, predictions, goals, and desires the customer has concerning the whole relationship (Jarvelin and Lehtinen, 1996). RQ is a manifest of positive relationship outcomes that reflect the strength of a relationship which meets the need and expectation of involved parties (Smith, 1998). Quality is particularly important to service firms because it has been shown to increase profit levels, reduce costs, and increase market shares. Moreover, service quality has been shown to influence purchase intentions, and is used by some firms to strategically position themselves in the marketplace (Meng \& Elliott, 2009), also positively affects one of behavioural outcomes - loyalty (Rauyruen \& Miller, 2007). Woo and Ennew (2004: 1256) we should accept a very general perspective on the meaning of the term quality relationship, as "an overall evaluation of the relationship between buyer and seller", and focus instead on identifying the constructs that constitute it. Some degree of industry or market specificity characterize these constructs. Research in the literature agrees that relationship quality is a higher- order construct consisting of several first-order constructs, among which trust, satisfaction with the salesperson and commitment to the relationship have been most commonly used (Athanasopoulou, 2009; Holmlund, 2008; Woo \& Ennew, 2004) thought that relationship quality is the main factor that affects customers' repurchasing behaviour. High relationship quality means that the customers are consistently satisfied with the performance provide by firms in the past consumption experience. Crosby et al. (1990).

\section{TRust:}

Trust is a willingness to rely on an exchange partner in which the firm has confidence (Moorman, Zaltman, and Deshpande, 1992). Trust is an expectation about an exchange partner that results from the partner's expertise, reliability, and intentionality (Ganesan, 1994). Trust plays a significant role in shaping interaction and long-term relationship building (Andersen \& Kumar, 2006; Dyan \& Di Benedetto, 2010; Huemer, 2004; Keh \& Xie, 2009). Trust as "the extent to which a firm believes that its exchange partner is honest and/or benevolent" or some variant thereof. Moorman et al.'s (1992) definition, similarly to that of Doney and Cannon (1997), reflects two components of trust: credibility and benevolence. Credibility reflects the customer's belief that the supplier has sufficient expertise to perform the job effectively and reliably, while benevolence reflects the extent of the customer's belief that the supplier's intentions and motives are beneficial to the customer even when new conditions arise about which a commitment has not been made (Ganesan, 1994). An interesting perspective on trust is that long- term relationships may not require trust; rather the relationship may be based on the necessity of having a supplier or distributor (Kumar, 2005). Although trust can be important at all stages of the relationship, the measurement of trust can only occur after a partner has been in a relationship long enough to evaluate this dimension. Similar to performance satisfaction, trust becomes of greater and measurable importance in the last two stages of relationship development.

\section{COMMITMENT}

Dwyer et al. (1987) see commitment as the highest stage of relational bonding. Relationship commitment (much like trust) is mainly interpreted as an attitude. Morgan and Hunt (1994, pp. 23) define the construct as "an exchange partner believing that an ongoing relationship with another is so important as to warrant maximum efforts at maintaining it; that is, the committed party believes. Commitment is a fundamental dimension of a working relationship (Hakansson and Snehota 1995). Commitment "captures the perceived continuity or growth in the relationship between two firms" (Anderson et al. 1994). It entails "a desire to develop a stable relationship, a willingness to make short term sacrifices to maintain the relationship and a confidence in the stability of the relationship" (Anderson and Weitz 1992, Morgan and Hunt 1994). Gundlach et al. (1995), identify three different dimensions of commitment: Affective commitment describes a positive attitude towards the future existence of the relationship. Instrumental commitment is shown whenever some 
form of investment (time, other resources) in the relationship is made. Finally, the temporal dimension of commitment indicates that the relationship exists over time. While the commitment attribution approach lends important insights, we follow the approach of other researchers who conceptualize commitment as an enduring desire to maintain a valued relationship (Moorman, Zaltman, \& Deshpande, 1992), and view it as separate from its attributions(Doney \& Cannon 1997; Kingshott, 2006; Morgan \& Hunt 1994; Rodriguez \& Wilson, 2002; Skarmeas, Katsikeas, \& Schlegelmich, 2002; Tellefsen \& Thomas, 2005; Wilson \& Mummalaneni, 1990). This approach allows for examination of the independent and antecedent effects of behavioral and emotional aspects of ties on the desire to maintain the relationship into the future. Also, this study does not examine how economic drivers influence commitment in these business rela-tionships (e.g. anticipated profits and mutual benefits).

\section{SATISFACTION:}

Satisfaction has been conceptualized to be a result of comparison to alternatives, as well as relationship reward, cost, and fairness (Johnson 1982; also see Ajzen 1977; Hatfield and Traupman 1981; Kelley and Thibaut 1978; Rusbult 1980; Thibaut and Kelley 1959). Thus, alternative attractiveness may reduce relationship satisfaction (Anderson and Narus 1984; Frazier 1983; Rusbult 1980; Thibaut and Kelley 1959). In summary, it is plausible that satisfaction and alternative attractiveness may also be simultaneously or bi-directionally (nonrecursively) associated. Similarly Ping (1993) reported that firms' satisfaction was positively associated with their use of voice (attempts to change rather than escape from objectionable relationship conditions) in a marketing channel. In discussing the study results, he proposed that it was plausible that firms' satisfaction increases their voice, but that their voice should subsequently increase these firms' satisfaction. Stated differently, he proposed that satisfaction and voice may also be bi-directionally or simultaneously. Dwyer, Schurr and Oh (1987) suggested that for exchange relationships in the committed stage of relationship development, satisfaction reduces the attractiveness of alternative exchange relationships. They commented that once a relationship reaches the committed phase where relationship satisfaction is high, the relationship parties do not stop noticing alternatives, but they maintain their awareness of alternatives without constant testing of the current relationship. Satisfaction constitutes a construct of vital importance inthe explanation of any type of relationship between two or more participants. It has been defined as a positive, affectivestate, resulting from the evaluation of all aspects of the relationship between one company and another Crosby LA, Evans KR, Cowles D 1990. Relationship quality in services selling: an interpersonal influence perspective. J Mark 1990. It therefore includes an evaluation of the economical and non-economical aspects of the relationship. In this way, economic satisfaction can be understood as a positive affective response that one of the participants has, with respect to the economic rewards, derived from the relationship in which they are immersed - margins, sales volume.

\section{MODEL AND HYPOTHESES}

\begin{tabular}{|c|}
\hline $\begin{array}{l}\text { Temporal } \\
\text { bond }\end{array}$ \\
\hline $\begin{array}{l}\text { Structural } \\
\text { bond }\end{array}$ \\
\hline Social bond \\
\hline
\end{tabular}

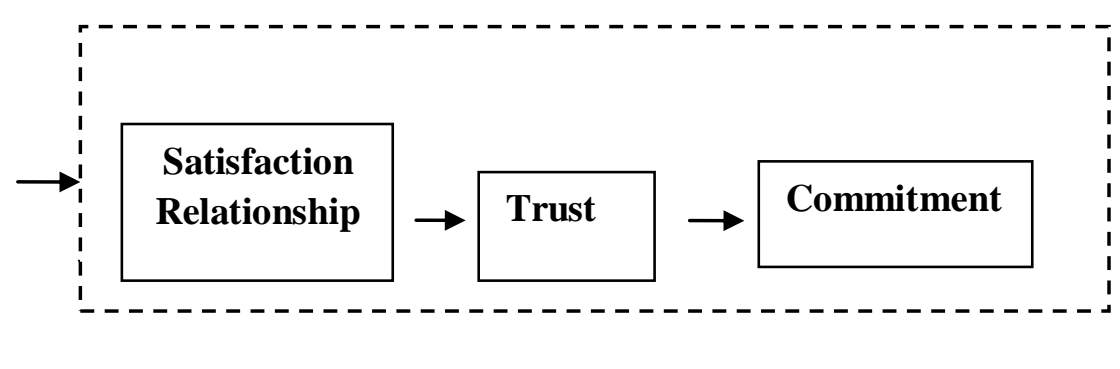

\subsection{TEMPORAL BOND AND SATISFACTION}

Gundlach et al. (1995) added a new dimension refers to the temporal dynamics of commitment, in your uniformity and stability over time (Becker, 1960; Scanzoni, 1979). Which refer to the desire to continue a relationship due to positive affect (Kumar, Scheer, \& Steerkamp, 1995b). Affect for and obligation (Gilliland \& Bello, 2002), unity (Kim \& Frazier, 1997) and emotional attachment (Fullerton, 2003). Many researchers consider these bond as essential variable to the strengthening the relationship of consumer intention behavioral (Berry, 1995, Berry and Parasuraman, 1991, Armstrong and Kotler, 2000 De Young, 1986 Christy, Gordon and Penn, 1996) and improving the quality o relationships (Garbarino and Johnson, 1999 Gruen, Summers and Acito, 2000). It suggests that the strength of a tie is a platform of both behavioral and emotional-based dimensions which in turn combines to develop commitment (Wilson \& Mummalaneni, 1990) and satisfaction 


\section{H1. The temporal bond is positively related to the satisfaction. SOCIAL BOND AND SATISFACTION}

Social bonding represents the norms and standards of conduct that are required for relationships, and these occur in the defining phase of relationship development as well as continuing to develop in Trust is a concept that has been described in different ways (Sako and Helper 1998). by this bond, the firm can understand what products or services customers need and want, and seller customized offerings accordingly. Thus, interdependent relationships are produced to make customers trust and feel satisfied with the firm, thus promoting relationship quality between both parties. Developing a mutual friendship has social effects; it can hardly be cloned by competitors.

\section{H2. The social bond is positively related to the satisfaction. STRUCTURAL BOND AND SATISFACTION}

The structural bonds offer target customers value-adding benefits that are difficult or expensive for customers to provide and that are not readily available elsewhere (Berry, 1995). Hsieh et al. (2005) defined structural bonds as the value adding services that are designed into a Web site-including knowledge and information about the industry and product customization-are not readily available elsewhere, and are expensive for customers to supply if they terminate the relationship. This bond is the most valuable dimension among relationship marketing, because it offers the solution of problems to critical customers. With this bond, the firm provides value-added benefits to customers, while such benefits are rare for customers and hardly satisfied by themselves. Since structural bonds offer several valuable services to customers which competitors usually cannot offer, this bond would raise the switching cost of customers. So, even though competitors intend to imitate by investing plenty of time and money, the effort cannot pay off.

\section{H.3 it is hypothesized that structural bonds are of the greatest importance in the satisfaction relationship SATISFACTION AND TRUST \\ Customer satisfaction leads to the development of trust and commitment, which is key to} maintaining a long-term relationship (Powers \& Reagan, 2007). Satisfaction is generally conceptualized as an attitudinal judgment about purchase (Jayawardhena et al, 2007). Customer satisfaction also has a significant affective component, which is created through repeated product or service usage. Satisfaction is commonly considered a prerequisite of customer retention and loyalty, as well as increased profitability and market share (Meng \& Elliott, 2009). Satisfaction is of the greatest importance in the trust

\section{H4. Satisfaction relationship is of the greatest importance in the trust TRUST AND COMMITMENT}

Trust is considered to be a key determining factor for commitment in the relationship structure (Dwyer et al., 1987; Morgan \& Hunt).Customer has more confidence in the seller" future performance when he evaluates the past performance level as satisfactory (Crosby et al. 1990). Ndubisi (2004) identified the constructs of RM as: trust, commitment, equity, and empathy. He defined trust as the partner's willingness to rely on the other partner with confidence and commitment as the desire of the partners to maintain the relationship due to a desire for mutually satisfying benefits. Equity is the perceived fairness in the buyer-seller relationship. Commitment is considered as a direct consequence of trust (Gurviez 2002). Both are the result of the relationship between seller and buyer; it is shown in previous studies concerning distribution channels (Morgan \& Hunt 1994), customers-firms relationships (Garbarino \& Johnson 1999) and interpersonal relations (Macintosh \& Lockshin 1997). Ganesan (1994) suggested that trust lessens potential risk and vulnerability within the relationship, thus leading to a greater long-term orientation. Furthermore, trust reduces transaction costs since there is not such a need to set up control mechanisms within the relationship (Jap \& Ganesan, 2000). As a consequence of this, these lower costs make it more likely that the relationship will continue in the future and that, therefore, the commitment to the relationship will become greater. Trust is of the greatest importance in the commitment .

\section{H5. Trust is of the greatest importance in the commitment}

\section{Methodology:}

The process for the research was as follows. A literature search provided the starting point for the operationalization of constructs in the hypothesised model. Eight exploratory interviews with managers were conducted and analysed to check face validity of the constructs. The interview analysis provided more items for inclusion in the questionnaire used to collect the data for the main analysis, which was achieved with structural equation modeling software. The following sections give more detail of this process. 


\section{MEASUREMENT INSTRUMENT DEVELOPMENT}

The scales used for this work have been adapted from previous research on business to business. Where those that were finally eliminated from the analysis are identified. Through a descriptive analysis of the data, a study of correlation matrix and an exploratory factor analysis was observed that there were no significant anomalies in them.

The scales, presented in the Appendix A, selected from the literature and adapted to fit the specific needs of this study. Reliability estimates are all within acceptable limits (Nunnally, 1978). All items used a 5point Likert scale $(1=$ strongly disagree, $5=$ strongly agree) unless otherwise noted. Kumar et al 1995 Gundlach et al. 1995 scale was used to measure temporal bond.

Han. 1991 Berry and Parasuraman work provided the scales we adapted to measure social and structural bond. Satisfaction was measured using scales developed by Geyskens et Steenkamp (2000). The measures for trust and commitment we adapted the scale of Morgan and Hunt (1994).

\section{RELIABILITY AND VALIDITY}

According to the two-step approach proposed by Anderson and Gerbing (1988), the reliability and validity of each construct is to be first examined and then a large set of measurement items is to be reduced to several or a single underlying factor. Finally, the structural model is developed and analyzed to test all the hypotheses. Kaiser-Meyer-Olkin (KMO) and Bartlett's Test of Sphericity was used to examine that the items are suited for the factor analysis. The principal component method of factor analysis, using the Varimax rotation procedure, was performed, and the number of factors was determined using eigenvalue $(\lambda>1)$. According to the testing, the KMO value of seven items of commitment was 0.789 and the Sphericity Test was significant at $\mathrm{p}<0.01$, representing that the items carry commonality. After the factor extraction, only one factor, explaining $67.44 \%$ of the variance, was extracted. Thus, it was named as "commitment."

Cronbach's alpha was assessed to check the reliability of measures. Table 1 shows the results of the reliability of each construct. All coefficient alpha values were greater than the threshold value of 0.70 suggested by Nunnally and Bernstein (1994), demonstrating high internal consistency and hence reliability of each construct.

Table 1: Reliability Test of Each Construct

\begin{tabular}{|c|c|c|c|c|c|c|}
\hline & \multicolumn{3}{|c|}{ Relational Bonds } & \multicolumn{3}{c|}{ Relationship Quality } \\
\hline Dimensions & $\begin{array}{c}\text { Temporal } \\
\text { Bonds }\end{array}$ & $\begin{array}{c}\text { Social } \\
\text { Bonds }\end{array}$ & $\begin{array}{c}\text { Structural } \\
\text { Bonds }\end{array}$ & Satisfaction & Trust & Commitment \\
\hline No. of items & 4 & 8 & 6 & 6 & 5 & 5 \\
\hline Cronbach's $\boldsymbol{\alpha}$ & 0.79 & 0.75 & 0.84 & 0.80 & 0.79 & 0.86 \\
\hline Cronbach's $\boldsymbol{\alpha}$ & \multicolumn{3}{|c|}{0.85} & \multicolumn{3}{c|}{0.87} \\
\hline
\end{tabular}

The confirmatory factor analysis was based on maximum likelihood estimation, which allows the assessment of whether the data support the hypothesized factor structure by $\chi^{2} / \mathrm{df}$, RMSEA (root mean square error of approximation), TLI (Tucker-Lewis index), CFI (comparative fit index), and SRMR (standardized root mean square residual). The factor analyses revealed that seven of 35 items had to be deleted to meet the required thresholds. With the exception of the construct contracting, each reflective construct had three or more items. The factor analysis supported the assumed factor structure since the fit indices all reflected acceptable model fit $\left(\chi^{2} / \mathrm{df}\right.$, TLI, CFI, , and RMSEA). Moreover, all Cronbach's alphas and composite reliabilities for the constructs as well as all indicator reliabilities clearly met the recommended thresholds. As can be seen in Table 1,contains detailed results of the factor analysis, including the recommended thresholds (Browne \& Cudeck, 1993; Churchill, 1979; Cronbach, 1951; Peter, 1981; Tabachnick \& Fidell, 2001). As shown on table 2.

Table.2: Measures of the Structural Model Fit

\begin{tabular}{|l|l|l|}
\hline Items & Measurement model & Criterion \\
\hline$\chi^{2}$ & 16,22 & \\
$\boldsymbol{d} \boldsymbol{f}$ & 7 & \\
\hline$\chi 2 / \boldsymbol{d} \boldsymbol{G F I}$ & 2,31 & $<3$ \\
\hline $\boldsymbol{G}$ & 0,939 & $\begin{array}{l}\text { Proche ou supérieur à } \\
0,90\end{array}$ \\
\hline
\end{tabular}




\begin{tabular}{|l|l|l|}
\hline $\boldsymbol{R M S E A}$ & 0,069 & $<0,08$ ou mieux $<0,05$ \\
\hline $\boldsymbol{C F I}$ & 0,961 & $\begin{array}{l}\text { Proche ou supérieur à } \\
0,90\end{array}$ \\
\hline $\boldsymbol{T L I}$ & 0,940 & $\begin{array}{l}\text { Proche ou supérieur à } \\
0,90\end{array}$ \\
\hline $\boldsymbol{C M I N / D F}$ & 1,8 & $\begin{array}{l}\text { petite possible, entre } \\
1,2-3, \text { voire 5 }\end{array}$ \\
\hline
\end{tabular}

We assessed discriminatory validity by relying on the Fornell Larcker test (Fornell \& Larcker, 1981). According to this test, sufficient levels of discriminatory validity are achieved if the AVE from each construct exceeds the squared correlations between all pairs of constructs. All pairs of constructs clearly fulfilled this requirement. Convergent and discriminant validity Establishing the validity component of a measure involves two elements: convergent validity and discriminant validity (Campbell and Fiske, 1959). Measures that lack convergent and discriminant validity can cause problems in the interpretation of a study's results (O'LearyKelly and Vokurka,1998). Convergent validity relates to the degree to which multiple methods of measuring a variable provide the same results (Churchill, 1979). The assumption is that if a measure is valid, it should yield the same results when utilized across different methods.

Table 3: contains information on the correlation coefficients between all constructs used.

\begin{tabular}{|c|c|c|c|c|c|c|}
\hline & 1 & 2 & 3 & 4 & 5 & 6 \\
\hline TEMP & 0,883 & & & & & \\
\hline SOCIA & $0,426^{* * * *}$ & 0,831 & & & & \\
\hline STRUC & $0,280 * *$ & $0,393 * *$ & 0,911 & & & \\
\hline SATIS & $0,443 * * *$ & $0,620 * * *$ & $0,415 * * *$ & 0,827 & & \\
\hline СОМM & $0,453 * * *$ & $0,223 * *$ & $0,361 * *$ & $0,705 * * *$ & 0,927 & \\
\hline TRUST & $0.469 * * *$ & $0.223 * *$ & $0.333 * *$ & $0.40 * *$ & $\begin{array}{l}0.04 * \\
*\end{array}$ & 0.789 \\
\hline
\end{tabular}

Discriminant validity is the degree to which measures of different latent variables are unique (Devellis, 1991). That is, in order for a measure to be valid, the variance in the measure should reflect only the variance attributable to its intended latent variable and not to other latent variables. Generally, convergent validity can be assessed from the measurement model by testing whether the reliability value (loading) of each individual indicator is above 0.50 with a significant $t$-value $T>2.0$ (Chau, 1997; Yeung, 1999). For the current study, all of the loadings of the indicators were higher than 0.50 . The t-values of the indicators were all above 2.0. These imply that the relationships between the indicators and the constructs are statistically significant, and provide satisfactory evidence of convergent validity for these sets of indicators. Tables show the reliability values of all the indicators.

Table 4: Fiability and validity of construct

\begin{tabular}{|c|c|c|}
\hline Construit & $\begin{array}{l}\text { Fiability ( } \rho \text { de } \\
\text { Jöreskog) }\end{array}$ & $\begin{array}{l}\text { Validity } \\
\text { Convergent (pvc) }\end{array}$ \\
\hline Temporal bond (TEM) & 0,787 & 0,524 \\
\hline Social Bond (SOCIA) & 0,796 & 0,533 \\
\hline Structurel Bond (STRUC) & 0,797 & 0,636 \\
\hline $\begin{array}{l}\text { Satisfaction Relationship } \\
\text { (SATIS) }\end{array}$ & 0,756 & 0,598 \\
\hline Trust (TRUS) & 0,935 & 0,860 \\
\hline Commitment (COMM) & 0.885 & 0.825 \\
\hline
\end{tabular}


Table 5: Results of structural equation modeling

\begin{tabular}{|c|c|c|c|c|}
\hline Path & Estimate & $\begin{array}{c}\text { factorial } \\
\text { weights } \\
\text { standarised }\end{array}$ & C.R. & P \\
\hline $\begin{array}{c}\text { Temporal bond } \rightarrow \\
\text { satisfaction }\end{array}$ & 1,951 & 0,860 & 7,55 & $* * *$ \\
\hline Social bond $\rightarrow$ satisfaction & 0,889 & 0,92 & 9,653 & $* * *$ \\
\hline $\begin{array}{c}\text { Structural bond } \rightarrow \\
\text { satisfaction }\end{array}$ & 1,000 & 0,78 & 5,477 & $* * *$ \\
\hline satisfaction $\rightarrow$ Commitment & 1,945 & 0,88 & 6,360 & $* * *$ \\
\hline Commitment $\rightarrow$ trust & 0,992 & 0,92 & 4,262 & $* 2$, \\
\hline
\end{tabular}

Critical ratios CR (Critical Ratio) found in Table 5 range from 4, 262 and 7,55 (CR must be greater than 2) $\mathrm{p}<1 \%$ (shown by $* * *$ ). All correlations between endogenous variables in our model are significant. The standardized factor loadings of the latent variables are greater than 0.76 indicate that the relational bonds have a positive influence on satisfaction. These results show that the temporal relationships, structural, social have a positive influence on satisfaction. The corresponding coefficients, respectively $0.86,0.92$ and 0.78 satisfy the hypotheses $\mathrm{H} 1, \mathrm{H} 2$ and $\mathrm{H} 3$. And there after satisfaction has on the one hand, the same direct impact on trust and commitment we can be concluded that H4 and H5 supported. According to Mills and Roux (2008), the commitment is still considered the antecedent of loyalty.

\section{Conclusions:}

\section{Conclusion And Directions For Future Research}

The results of this research provide important information to managers engaged in the process of maintaining long-term buyer - seller relationships. This study tested whether a bond relationship has an impact on quality relationship, buyer satisfaction, trust, commitment, and the relationships between these variables. The motivation for this research was the observation that few empirical studies test bond relationship in buyersellers relationships with relational bond. We believe our results have both managerial and theoretical implications, and we discuss these before addressing the limitations of our work as well as avenues for future research. The aim of this study was to test a hypothesized model of bond relationship in business-to-business buyer-seller relationships and a set of scales for temporal social and structural Assessment. Analysis of the data obtained in the study supports the hypothesised scales as measures of the bond relationship construct and its relationship with Quality relationship. The unidimensionality of the scales has been strongly established by the use of confirmatory factor analysis. This study contributes to the body of knowledge by suggesting the ways to build long-term relationship with customers in a context business to business, including information about the nature of bonds between buyers and sellers and the relationship among relational bonds, relationship quality. The results indicate that the social bond has a greater impact on relationship quality for satisfaction and trust than for commitment. Moreover, adopting social bond strategies can maintain good relationship quality with customers and inspire their strong loyalty. Because consumers cannot judge the performance of experience and credence services easily, they would first seek information from friends, relatives, or acquaintances. If sellers can have favorable repeated interactions with buyers through e-mails or blogs to reduce their apprehension, they will trust and be satisfied with the sellers and maintain long-term relationships with sellers. Relational bonds have a positive effect on relationship quality. Moreover, a specific relational bond would have a greater impact on relationship quality in different products. If sellers can maintain good relationship quality with buyers, they could enhance the latter's long-term loyalty. This study suggests that sellers should adopt different bonding strategies according to the degree of difficulty to evaluate the product type they put on sale.

\section{Research Limitations and Suggestions for Future Research}

one limitation in this study is that of the sampling method a convenience sampling was utilized and the respondents were limited to the residents of Casablanca and Rabat area, and therefore generalizing to all service sectors should be done with care.

The analysis presented here is based upon a large sample in the sector service, making us optimistic about the positive results that we report. However, we are still cognisant of the fact that we report on only monadic data, with no reference to the views of the counterparts in the relationship. In order to do this, dyadic 
measures that collect data from both buyer and seller in a particular relationship could be used to enrich future analyses (Gulati and Sytch, 2007).

This research explains relationships among relationship quality, Temporal, Social, Structural Satisfaction, Trust, and Commitment in a Business to Business context. Understanding why and how some business relationships succeed while others fail are perhaps among the central questions for firms. From the managerial perspective, it is then important to know how to improve overall performance. Based on our study of business relationship and considering the context in which our respondents are embedded, it is possible to state that performance is directly affected by relational bond. Managers may use our study to assess the adequacy of their business collaboration sellers buyers in terms of its functional advantages of the information. Furthermore, we discuss the relational bond from the perspective of designing interfirm collaboration that allows for creative joint problem solving. Managers should also be engaged in trust-enhancing activities because it can foster impact on quality relationship.

\section{Reference}

[1] Bendapudi N. \& Berry L.L. (1997). Customers' motivations for maintaining relationships with service providers, Journal of Retailing, 73, 1, pp. 15-27.

[2] Castro, L.M., Alves, G.A. \& Proenca, J.F. (2005). The Key Dimensions in the Development of the Consultant-Client Relationship: a Suggestion for a Business Relationship

[3] Naude, P., Buttle, F. (1999): Assessing Relationship Quality in Mcloughlin, D., and Horan, C. (eds.), Proceedings of The 15 Annual IMP Conference, University College, Dublin, CD-ROM

[4] Chen, Z. (2003). Consumers' value perception of an e-store and its impact on e-store loyalty intention. PhD Thesis, United States -Indiana, Purdue University.

[5] Crosby, L.A., K.R. Evans and D. Cowles (1990), "Relationship Quality in Services Selling: an Interpersonal Influence Perspective," Journal of Marketing, 54, 68-81.

[6] Granovetter, M. (1985) Economic action and social structure: The problem of embeddness, In American Journal of Sociology Volume: 91. No.3, pp.481-510

[7] Hakansson, H. ed. (1982) International Marketing and Purchasing of Industrial Goods: An Interaction Approach, Chichester, John Wiely \& Sons

[8] D.Y. Lee, P.L. Dawes, « Guanxi, trust, and long-term orientation in Chinese business markets », Journal of International Marketing, Vol. 13, $\mathrm{N}^{\circ} 2$, p. 28-56, 2005.

[9] De Wulf, K., Odekerken-Schröder, G., and Iacobucci, D. (2001). Investment in Consumer Relationships: A Cross-Country and Cros Industry Exploration Journal of Marketing, 65, 33-50

[10] Doney P. M. et Cannon J. P. (1997), An Examination of the nature of trust in buyer-seller relationships, Journal of Marketing, 61, 2, $35-51$

[11] Dorsch, M.J., S.R. Swanson and S.W. Kelley (1998), "The Role of Relationship Quality in the Stratification of Vendors as Perceived by Customers," Journal of the Academy of Marketing Science, 26(2), 128-142.

[12] Dwyer F. R., Schurr P. H. et Oh S. (1987), Developing buyer-seller relationships, Journal of Marketing, 51, 2, 11-27.

[13] Ford D. (1980) The developpement of buyer-seller relationships in industrial markets, European Journal of Marketing, 14, 5/6, 339353.

[14] Fornell, C., \& Larcker, D. F. (1981). Evaluating structural equation models with unobservable variables and measurement error. Journal of Marketing Research, 18(1), 39-51

[15] Ganesan S. (1994), «Determiants of Long-Term Operation in Buyer-Seller Relationships », Journal of Marketing, vol. 58, n², April;

[16] Garbarino, E. and Johnson, M.S. (1999), The different roles of satisfaction, trust and commitment in customer relationships, Journal of Marketing, 63, 2, 70-87.

[17] Geyskens I., Steenkamp J.-B.E.M. and Kumar N. (1998), "Generalizations about trust in marketing channel relationships using meta-analysis", International Journal of Research in Marketing, 15, pp.223-248

[18] Gundlach G., Achrol, R.S., et Mentzer J.T., (1995), The structure of commitment in exchange, Journal of Marketing, 59, January, 78-92.

[19] Heide J. B. et John G. (1990), « Alliances in industrial purchasing: The determinants of joint action in buyer supplier relationships », Journal of Marketing Research, 27, 1, 24-36.

[20] Hibbard, J. D., Kumar, N. and Stern, L. W. (2001). Examining the impact of destructive acts in marketing channel relationships., Journal of Marketing Research, 38 (1), 45-61

[21] Hill, C. (1990), Cooperation, opportunism, and the invisible hand : implications for transaction cost theory, Academy of Management Review, Vol. 15, n³, pp. 500-513.

[22] Hinde R. A. (1997), Relationships: A dialectical perspective, Psychology Press, Hove

[23] Holmlund, M. et S. Koch (1996), «Buyer Dominated Relationships in a Supply Chain - A Case Study of Four Small-sized Suppliers», International Small Business Journal, vol. 15, no 1, p. 26-40.

[24] Jap, 1999). Jap S.D. (1999), « Pie-Expansion Efforts: Collaboration Processes in Buyer-Supplier Relationships », Journal of Marketing Research, vol. 36, November, pp. 461-475.

[25] Johanson J. et Mattson L.G. (1987), «Interorganizational Relations in Industrial Systems : A Network Approach compared with the Transaction Cost Approach », International Studies of Management and Organization, vol. 18, n 1, p. 34-48.

[26] Kaufmann P.J, et Stern. L.W. (1988), Relational Exchange Norms, Perceptions of Unfairness, and Retained Hostility in Commercial Litigation, Journal of Conflict Resolution, 32, 3, 534-552.

[27] Mattson, L.G. (1985), An application of a network approach to marketing: Defending and changing marketing positions, eds. N. Dholakia and J. Arndt, Changing the Course of Marketing Alternative and Paradigms for Widening Marketing Theory. Greenwich, JAI press.

[28] Mattsson, L. G. (1987): Management of Strategic Change in a "Markets-as-Networks" Perspective, Chapter 7 in The Management of Strategic Change, A Pettigrew Blackwell, 234-256

[29] McCall, G. J. (1970): The Social Organization of Relationships, in McCall, G.J., McCall, M. M., Denzin, N. K., Suttles, G. D., Kurth, S. B. (Eds.), Social Relationships, Aldline Publishing Company, Chicago, 3-34 
[30] Morgan et Hunt (1994), Morgan, RM., and Hunt, S.D., 1994. The commitment-trust theory of relationship marketing. Journal of Marketing. 58 (July), 1994.

[31] Noordewier T.G., John G. et Nevin R. (1990), Performance ourcomes of purchasing arrangements in industrial buyer-vendor relationships, Journal of Marketing, 53, 2, 80-93

[32] Noordewier T.G., John G. et Nevin R. (1990), Performance ourcomes of purchasing arrangements in industrial buyer-vendor relationships, Journal of Marketing, 53, 2, 80-93.

[33] Palmatier R. W., Dant R. P., and Evans K. R. (2006), Effectiveness of relationship 24Marketing - Meta-analysis, Journal of Marketing, 70, 4, 136-153.

[34] Parkhe, A. (1993), Strategic alliance restructuring : a game theoretic and transaction cost examination of interfirm cooperation, Academy of Management Journal, Vol. 36, $\mathrm{n}^{\circ} 4$, pp. 794-829.

[35] Ryu, S., Park, J.-E., et Min, S. (2007), Factors of determining long-term orientation in interfirm relationships, Journal of Business Research, Vol. 60, n 12 , pp. 1225-1233.

[36] Sheth J.N. \& Parvatiyar A., 1995, The Evolution of Relationship Marketing, International Business Review, 4, 4, pp. $397-418$.

[37] Smith, M.L. (1998), One to one: put the customer in the information driver seat and build better relationships, Direct Marketing, 60, 9, 37-40.

[38] Smith, M.L. (1998), One to one: put the customer in the information driver seat and build better relationships, Direct Marketing, 60, 9, 37-40.

[39] Tuten, T.L. \& Urban, D.J. (2001). An Expanded Model of Business to- Business Partnership Formation and Success. Industrial Marketing Management, 30, 149-164.

[40] Wilson, David and V. Mummalaneni. 1986. "Bonding and Commitment in Supplier Relationship: A Preliminary Conceptualization." Industrial Marketing and Purchasing 1: 66-58.

[41] Wilson, D.T. (1995). An Integrated Model of Buyer-Seller Relationships. Journal of Academy of Marketing Science, 23 (4), $335-345$ 